\title{
California
Manageview
}

\section{Implementing a Digital Strategy: Learning from the Experience of Three Digital Transformation Projects}

\begin{tabular}{|c|c|}
\hline Journal: & California Management Review \\
\hline Manuscript ID & CMR-03-19-000002-IP-DT.R2 \\
\hline mstype: & Invited Paper - Digital Transformation \\
\hline $\begin{array}{r}\text { Keyword }<\text { br }><\text { br }>\text { IMPORTANT } !</ b> \\
\text { Authors must select at least } 5 \\
\text { keywords from list. If desired } \\
\text { keyword does not appear, choose } \\
\text { keyword with closest representation. } \\
\text { Add keywords not found in our list in } \\
\text { the } 2 \text { nd Keyword section below this.: }\end{array}$ & $\begin{array}{l}\text { Business strategies, Case studies, Data management, } \\
\text { Implementing strategy, Strategic management }\end{array}$ \\
\hline \multirow[t]{2}{*}{$\begin{array}{r}\text { Keyword }<\text { br }><\text { br }>\text { This section is } \\
\text { optional }</ \mathrm{b}\rangle \text {, and you can use it to } \\
\text { identify important keywords for your } \\
\text { article that you could not find in our } \\
\text { list in the previous section.: }\end{array}$} & digital transformation, digital strategy, strategy implementation \\
\hline & $\begin{array}{l}\text { The recent development of digital technologies and the } \\
\text { extraordinary amount of data that devices and applications collect } \\
\text { each day increasingly drive companies to radically transform the } \\
\text { business architecture through which they create and appropriate } \\
\text { value. However, companies may fail to extract value from digital } \\
\text { transformation due to the disconnection between strategy } \\
\text { formulation and strategy implementation. Accordingly, this work } \\
\text { aims to unearth the anatomy of the process through which } \\
\text { companies implement a digital transformation strategy. Through } \\
\text { the analysis of three case studies, we construct a framework that } \\
\text { supports companies in implementing a digital transformation } \\
\text { strategy and thereby innovate their business model. }\end{array}$ \\
\hline
\end{tabular}

\section{SCHOLARONE ${ }^{m}$ Manuscripts}




\title{
Implementing a Digital Strategy: Learning from the Experience of Three Digital Transformation Projects
}

\begin{abstract}
The recent development of digital technologies and the extraordinary amount of data that devices and applications collect each day increasingly drive companies to radically transform the business architecture through which they create and appropriate value. However, companies may fail to extract value from digital transformation due to the disconnection between strategy formulation and strategy implementation. Accordingly, this work aims to unearth the anatomy of the process through which companies implement a digital transformation strategy. Through the analysis of three case studies, we construct a framework that supports companies in implementing a digital transformation strategy and thereby innovate their business model.
\end{abstract}

Keywords: digital transformation; digital strategy; strategy implementation.

$$
\begin{array}{r}
\text { "Many companies define great digital transformation strategies, but there is a huge difference between having a } \\
\text { well-reasoned digital strategy on paper and successfully implementing it [...] Most digital transformation } \\
\text { projects fail due to poor strategy execution" }
\end{array}
$$
Adriano Gerardelli, Director of Digital Strategy \& Innovation, PricewaterhouseCoopers (PwC)

The remarkable progress of digital technologies and the increasing pervasiveness and reliability of high-speed internet services have radically reshaped the operations and business models of companies ${ }^{1}$, leading to a series of substantial changes in their activities, processes, and capabilities ${ }^{2,3}$. Actually, a growing number of companies have adopted a digital transformation strategy, i.e., a strategy leveraging digital technologies to transform how they 
create and appropriate value. Of course, adopting digital transformation strategies requires companies to question and revise the current architecture of their value creation and appropriation models, and effectively assimilate the disruption ensuing from the introduction of digital technologies to sustain their competitive advantage.

In this regard, a requirement for firms adopting digital transformation strategies is renewing their business models in light of the changes that digital transformation induces, so that the new digitally enabled business model is consistent with the business strategy, thereby leading to superior competitive performance. ${ }^{4,5,6}$

In particular, the pervasiveness of new digital technologies allows: i) increasing the flexibility of products and services by supporting the continuous evolution of their scope, features, and value, even after they have reached the market; ${ }^{7}$ ii) lowering the barriers across industries, favoring connections, exchanges, and partnerships among companies operating in different sectors; ${ }^{8}$ and, iii) supporting companies in accessing continuous, timely, and reliable data streams. ${ }^{9}$

Digital transformation may lead to notable advantages for firms, such as products and services that are more efficient and consistent with customer needs, ${ }^{10}$ a shorter innovation process and time to market, ${ }^{11}$ extending the offering and creating related digital ecosystems. ${ }^{12}$ Moreover, digital transformation favors the interconnection among different industries, by leading firms in reaping new opportunities to create and appropriate value through the digitization and connectivity ${ }^{13}$. For instance, Becton Dickinson, a medical equipment manufacturer, has been developing interests related to the software industry and analytics to increase the effectiveness of its products ${ }^{14}$. Also, the attention of companies as Google, Apple, and Uber towards the automotive industry, through the development of autonomous vehicles, is another example of how digital transformation reduces barriers between different industries. 
However, the adoption of digital transformation strategies also entails relevant challenges. ${ }^{15,16,17}$ In fact, according to recent estimates, $66 \%$ to $84 \%$ of digital transformation projects fail, ${ }^{18}$ which is a vast number considering the costs, both monetary and otherwise, of putting in place these projects. One major challenge refers to ensuring consistency between strategy formulation and strategy implementation ${ }^{19,} 20,21$, which despite their interdependence are deemed distinct concepts. Specifically, digital strategy formulation refers to defining a guiding policy on creating and appropriating value by exploiting digital technologies to achieve long-term objectives, considering factors related to the external environment, the technological potential in the current competitive scenario, and the market evolution. Therefore, digital strategy formulation should identify the elements of the firm's business model that must be modified according to the new strategy, as well as the scope of the digital transformation.

Differently, digital strategy implementation refers to how firms translate the digital strategy formulated into a concrete plan and set of actions, ${ }^{22,23,24}$ i.e., how they put into effect the new digitally enabled business model. Therefore, the careful implementation of a digital strategy is crucial to ensure consistency between the firm's actions and the objectives defined in the digital strategy formulation. ${ }^{25}$

In fact, the existing body of knowledge implicitly assumes that once a digital transformation strategy has been defined, implementation will follow (e.g., ${ }^{26,27}$ ). However, corporate practice shows that this is not the case, and senior executives cannot achieve any benefit from digital transformation strategies if they cannot effectively implement them. ${ }^{28,} 29$ Extant studies point out that effective strategy implementation is more critical to avoid failures as compared to good strategy formulation ${ }^{30,31}$, since on the one hand a precise implementation allows to adapt to evolving conditions ${ }^{32}$, thus correcting for an inaccurate formulation $^{33}$, on the other hand a good formulation is not valuable if not properly executed ${ }^{34}$. 
A prominent example of this is General Electric (GE). In the last seven years, GE's top management planned to digitally transform the firm. However, while deemed an appropriate strategic choice in the current competitive environment, GE failed to implement this strategy to the point of having to fire over 100 employees at the software operation facility that had been created to support GE's digital strategy. ${ }^{35}$ Recently, John Flannery, GE's CEO, pointed out that the company is "still deeply committed to [digital], but we want a much more focused strategy." ${ }^{36}$ Given such disconnection between strategy formulation and implementation, and the crucial importance of implementation for a digital transformation strategy to succeed also in relation with formulation ${ }^{37,38,39,40}$, our aim is to understand how firms can implement a digital transformation strategy. Specifically, we describe and analyze three cases of firms that digitally transformed their business (i.e., $\mathrm{ABB}, \mathrm{CNHi}$, and Vodafone), supported by a "digital companion" globally renowned for its excellence in the execution of digital transformation strategies, namely, Microsoft. The rich body of qualitative evidence allowed us to identify the critical resources, capabilities, and activities, as well as the stakeholders that need to be taken into account when a firm implements a digital transformation strategy, i.e., the building blocks of a digital transformation strategy. These building blocks make up our framework illustrating the main pillars that the companies we analyzed used to ensure consistency between their strategy formulation and implementation, thus leading to successful digital transformation projects. In particular, since digital transformation strategies may substantially change how companies create and appropriate value, this emerging framework allows companies to renew their business models, conceived as the "conceptual and architectural implementation of a business strategy." 41, 42

Our study offers a number of contributions to theory and practice. From a theoretical standpoint, we contribute to the emerging literature stream on digital transformation. $43,44,45$ 
In particular, we illustrate how three companies (ABB, CNHi, and Vodafone) implemented a digital transformation strategy with the support of Microsoft. Based on the building blocks identified, we highlight the paramount importance of appropriate strategy implementation and consistency with strategy formulation for a successful digital transformation. ${ }^{46,47}$ Moreover, our findings also contribute to the digital transformation literature $48,49,50$ by suggesting a link with the business model literature. Our qualitative evidence shows that when implementing a digital strategy, companies must rethink their business model and how this will impact on the processes and people involved. The building blocks of our inductively developed framework offer guidance in this process. Therefore, while prior studies investigated digital transformation by adopting multiple perspectives, as dynamic capabilities ${ }^{51}$, information systems ${ }^{52}$, and resource-based view ${ }^{53}$, in line with other studies discussing the relationship between digital transformation and business models (for example, ${ }^{54,55}$ ), we provide an analysis and discussion of the building blocks of a digital business model, suggesting a framework that may favor the implementation of digital transformation strategies.

From a practical standpoint, this work proposes an actionable framework to which practitioners can refer to effectively steer the implementation of a digital transformation strategy. Indeed, firms may use the emergent building blocks that constitute the framework as a checklist to ensure and verify the internal consistency between strategy implementation and strategy formulation, thereby increasing the likelihood of a successful digital transformation.

\section{Conceptual Background}

The increasing diffusion of new digital technologies is disrupting existing industries. ${ }^{56} \mathrm{In}$ fact, a growing number of companies leverage these digital technologies to radically revise how they create and appropriate value, in other words, they are adopting a digital transformation strategy. Indeed, due to digitalization, many products and services offer new 
features and functions. A prominent example is the Nest thermostat, which alongside the traditional functions increases energy use efficiency by collecting data on energy consumption, sharing these with utilities for more accurate forecasting, improving the service, providing customers with suggestions to reduce energy consumption and connecting other home devices. ${ }^{57}$ Another notable example of a company that has completely and successfully revised its business thanks to digitalization is Netflix. Originally, Netflix was an online DVD-by-mail sales and rental store. However, consequent to the boost in data connection speed and its lower costs, as well as improvements in video-on-demand service effectiveness and efficiency, Netflix digitally transformed its competitive strategy by offering a worldwide video streaming service, exploiting data on movie consumption to understand major trends in the entertainment business, and eventually becoming an original content producer. ${ }^{58,59}$ As these two examples show, the pervasive use of digital technologies and the ability to collect consumption and utilization data enable companies to rewire their traditional business model into a digital business model ${ }^{60}$ that may lead to increasing their competitive advantage.

However, digital transformation is not always straightforward. Indeed, due to the disruption in activities, processes, and capabilities, digital transformation processes often fail. ${ }^{61}$ In fact, several examples show that despite the appropriateness of adopting a digital transformation strategy, the outcomes may be far from those expected. For instance, as in the GE case, Nike failed to reap the benefits of digital transformation with its Nike+ personal fitness products. ${ }^{62}$ Nike + products incorporated sensors that collected data on customer activities, and synchronized these through a web platform. In this way, customers could receive feedback and suggestions to improve their physical performance, along with the possibility to access a virtual community of friends, athletes, and coaches. ${ }^{63}$ In turn, Nike could collect data on customers, their activities, and preferences, to fine-tune its marketing 
activities. ${ }^{64}$ However, while the digital transformation project was promising, Nike discontinued its Nike+ products, ${ }^{65}$ and only recently attempted to apply digital technologies to achieve a different objective. ${ }^{66}$

The reasons why digital transformation projects fail are manifold, although a major one consists in the disconnection between the formulation of a digital transformation strategy and its implementation, including the failure to consider important aspects of change management in relation to employees and customers who are required to change their way of working and interacting with the brand. Indeed, developing a proper strategy for effectively leveraging digital technologies is crucial for the success of digital transformation projects ${ }^{67,68,69}$. Specifically, the adoption of digital technologies may generate substantial change in a firm's processes, activities and resources that calls the firm itself to thoroughly rethink how it generates and appropriates value. Actually, defining a digital transformation strategy corresponds to developing a contingent plan of action to achieve a specific goal ${ }^{70}$ through the strategic renewal of the firm ${ }^{71}$. However, despite formulating an appropriate digital transformation strategy to create value and increase their competitive advantage, companies may fail in implementing the strategy, i.e., defining and executing a plan to effectively create and appropriate value. Strategy implementation is particularly risky and uncertain in digital transformation projects, since companies have to deal with a disruptive change to their business, following the introduction of new digital technologies. ${ }^{72}$

In order to effectively support the actual implementation of a digital transformation strategy, firms may rely on business models which are deemed as the reflection of the firms' realized strategy ${ }^{73}$. In fact, business models are conceptual tool used to depict how firms create and appropriate value, adapting the previously defined strategy to the contingencies that actually take place ${ }^{74,75}$. Hence, they represent a logical structure favoring the linkage between the formulated strategy with its contingent implementation ${ }^{76,77}$. Indeed, business 
models describe the elements and the relationships leveraged by firms to create and appropriate value ${ }^{78}$. In particular, from a strategic viewpoint, business models are made of four main components ${ }^{79,80}$ : i) the firm's value proposition and market segments, ii) the structure of the value chain, iii) the mechanisms used by the firm to appropriate the value provided, and iv) the relationships among these elements. Therefore, they contribute to provide a complete description of a firm's strategy ${ }^{81}$ and can hence be helpful when companies are called to thoroughly revise their strategies due to disruptive changes, ${ }^{82}$ such as those linked to digital transformation.

As shown in the aforementioned examples, a digital transformation may require a substantial change in the business model and appropriately managing the transition with new processes, activities, resources and capabilities to reap the maximum advantages from the digital transformation and reduce the cost burden. ${ }^{83}$ In a digital transformation strategy, the role of business model is paramount to support the integration between strategy formulation and strategy implementation, and adapt the architecture connecting the firm's value proposition, market segments, value chain, and value appropriation to the emerging contingencies due to the adoption of digital technologies. ${ }^{84}$

However, to effectively adapt the business model to the changes that digital technologies induce, and hence ensuring consistency between digital strategy formulation and implementation, its main elements must be representative of, and consistent with, the digital transformation undertaken. In fact, the introduction of digital technologies calls into question the traditional way of doing business ${ }^{85}$ and companies must thus reconsider which elements to leverage to establish and sustain their competitive advantage. ${ }^{86}$ The Nest and Netflix cases are exemplars in this regard.

Furthermore, identifying the core aspects behind a digital strategy and its implementation allows companies to apply the digital lens to their current business, ascertain new modes of 
value creation, evaluate new ways of value appropriation, ${ }^{87}$ and consequently renew their strategies. ${ }^{88}$ For instance, while data streams are paramount for firms adopting digital technologies, ${ }^{89}$ traditional business model frameworks (for example, ${ }^{90}$ ) do not assign them the central role they have in supporting the digital transformation.

Accordingly, in this study, we aim to understand how firms can effectively implement a digital strategy by highlighting the core aspects that may concur to define a digital business model.

\section{Research Design and Methodology}

We attempt to answer our research question by adopting a case study methodology 91,92 and the principles of engaged scholarship. ${ }^{93}$ Indeed, one of the authors is a Microsoft manager who directly followed several digital transformation projects on behalf of her company. Notably, Microsoft has in recent years increasingly partnered with companies wishing to transform their businesses by leveraging data and technologies, thus becoming an influential player in the digital transformation ecosystem. Acknowledging the difficulties that enterprises may face in embarking on digital transformation processes, and exploiting the related capabilities and knowledge, Microsoft has positioned itself as a partner aiming to accompany firms along this journey with a structured methodology and the potentialities of its technologies, thus becoming a strategic "digital companion" for organizations embracing a digital transformation strategy. Satya Nadella, Microsoft's CEO, explained this strategic vision, noting:

"Companies are focused on ensuring that they stay relevant and competitive by embracing this [digital] transformation. And we want Microsoft to be their partner. To do so, there are four initiatives every company must make a priority. The first is engaging their customer base by leveraging data to improve the customer experience. Second, they 
must empower their own employees by enabling greater and more mobile productivity and collaboration in the new digital world of work. Third, they must optimize operations, automating and simplifying business processes across sales, operations, and finance. Fourth, they must transform their products, services, and business models." 94

Given the vision and commitment to partnering with firms to help them digitally transform their businesses, the analysis of three companies that Microsoft accompanied provides an extraordinary opportunity to observe how digital transformation strategies are implemented with the assistance of an expert and distinguished companion. Indeed, Microsoft's unique experience in accompanying firms in the implementation of a digital transformation strategy was fundamental to identifying the specific building blocks that constitute the framework we constructed from our analysis.

Concerning our sampling strategy, we selected digital transformation projects that had involved Microsoft and can be considered exemplar as well as particularly insightful for the implementation of a digital transformation strategy. ${ }^{95}$ More in detail, the author who is a Microsoft manager critically revised the portfolio of projects she has participated in during the last 5 years with the idea to build a polar type sample, which included both successful and unsuccessful cases of digital strategy implementation. The idea was to critically compare implementation projects that delivered positive results, with those that instead were unsuccessful, to more easily spot differences and unearth factors linked with successful digital strategy implementation. Unfortunately, due to privacy and confidentiality reasons, it was not possible to have access to the data required to carefully study the unsuccessful cases. Therefore, we decided to focus on cases that were illustrative examples of a successful alignment between strategy formulation and implementation in different contexts (in particular, manufacturing and service companies), to allow for potential differences among cases. Following these criteria, the case selection brought to our attention three cases of 
organizations that successfully implemented a digital transformation strategy, namely, ABB, $\mathrm{CNHi}$, and Vodafone, allowing us to highlight the critical elements to take into account to effectively implement a digital transformation strategy. Thanks to the direct involvement in the realization of these projects of one of the authors, we have had privileged access to data and information that were especially useful to inductively build a model of digital strategy implementation.

Data from the cases were collected using primary and secondary sources. In particular, one of the authors, affiliated with Microsoft, was directly involved in the digital transformation implementation in the three cases, working on the execution of these projects for an average period of 12 months each, consistently with the engaged scholarship methodology. ${ }^{96}$ She had the opportunity to take part in the projects and access primary sources of information, such as aggregated data, internal archival records and reports, and interviews with those involved in the digital transformation processes, thus able to directly scrutinize the actual implementation process. In particular, the interviews were based on a structured list of questions, designed to provide a clearer understanding of the digital transformation processes and on the business model renewal. Moreover, interviewees were encouraged to share further insights that could support the research team to get a clearer picture of the processes. Furthermore, secondary sources, including corporate websites and business magazine articles, enabled obtaining a clear picture of the processes in place and triangulating the emerging body of evidence. The data were gathered in 2018 and refer to the period 2016-2018. Table 1 reports some general information on the cases.

[Insert Table 1 about here]

The researchers then analyzed the data collected following an inductive approach. The authors independently reviewed the cases to identify the building blocks supporting the 
implementation of a digital transformation strategy. In the first phase, each author coded and labelled the transcripts of the interviews and other primary and secondary sources documents, in order to highlight features related to the business model transformation of each case and referring to typical business model elements. ${ }^{97,} 98$ Afterwards, the results of this phase were compared across cases, to spot for similar patterns and emerging concepts ${ }^{99}$. Thereafter, the individual outputs were discussed and synthesized during ad hoc meetings to construct the proposed framework. In particular, the definition of the business model elements to be included in the proposed framework was consistent and representative with regard to the theoretical understanding about business model elements (i.e., firm's value proposition and market segments, value chain structure, value appropriation mechanisms, and relationship among these elements) ${ }^{100,101}$. Actually, during this phase the emerging results were continuously compared with the literature, to spot confirming and conflicting findings, with respect to the extant knowledge. In this way, we corroborated the internal validity and increased the generalizability of our results, hence adding further reliability ${ }^{102}$. Finally, we asked our key informants whether they felt the framework was a reasonable description of what had occurred at the companies in light of their own experiences, and all agreed, as did the Director of Digital Strategy \& Innovation at PricewaterhouseCoopers who found it a good and useful induction of the business models building blocks to consider for the implementation of a digital strategy.

\section{Overview of the Three Cases}

In this section, we present the three cases investigated, namely, $\mathrm{ABB}, \mathrm{CNHi}$, and Vodafone, and provide insights and details on the digital transformation projects they undertook with Microsoft's support.

ABB. ABB is a Swiss company established in 1988 that operates in power and automation technology development with utilities and industrial firms as customers. ABB's 
digital transformation project began in 2016 and focused on creating additional value for customers by providing software-enabled services. ABB's business model essentially evolved from a traditional model aimed at simply selling products and providing a basic maintenance service to a servitized model. ABB's objective was to offer a pay-per-use service for specific devices, and to do so, had to embrace digital transformation to continuously sense the state of devices and offer digital support services, such as predictive maintenance, forecasting, and optimization. The digital transformation project was part of this journey and involved people from different functions. Specifically, 30 employees from R\&D, Product Management, Sales, Marketing and Communication were involved in this digital transformation project.

CNHi. CNH Industrial, registered in the Netherlands with corporate offices in London, was founded in 2012. CNHi's core business is the design and production of agricultural and construction equipment, commercial vehicles, and powertrains. CNHi also offers financial services to its customers. The digital transformation project under study focused on the agricultural equipment business. In particular, CNHi is committed to guiding the evolution of the agricultural industry, supporting the development of the digital farming paradigm. Specifically, CNHi aims to connect all the stages of farming through a digital platform to offer automation capabilities, value added services, connect customers with internal and external partners, and promote a servitized business model. The digital transformation project analyzed began in 2018 and aimed to develop autonomous unmanned agricultural machines endowed with Artificial Intelligence (AI) that operate through a digital platform. 30 employees were involved in the project, including managers from the commercial vehicles unit, industry-specific vehicles unit, as well as Information Technology (IT), operations, and executive business stakeholders.

Vodafone. Vodafone is a UK-based company founded in 1991 and operating in the telecommunications industry. Vodafone is a mobile operator present in 25 countries in 
Europe, Africa, Asia, and Oceania, while also covering the Americas with partnerships. Vodafone's digital transformation project began in 2017 and was focused on improving its customer care services, deemed critical to retaining customers. Specifically, Vodafone's objectives were cost reduction, customer care process optimization, and improving digital interaction with customers through AI. Accordingly, Vodafone leveraged Microsoft's digital services to develop conversational autonomous interfaces based on neural networks processing natural language, able to interact with customers through several channels (e.g., voice, apps, social networks, websites, home assistants). The project initially involved 5 employees from the IT unit and 23 from the commercial operations unit. Moreover, thanks to a successful process of change management and new operating model implementation, the project has added now several digital hubs that operate following agile methodologies in developing their new digital products with an incremental and iterative approach. This digital transformation project is redefining the way Vodafone listens, understands, and assists end customers, which after rolling it out in Italy, will be extended to other countries in which Vodafone operates.

\section{Findings}

The analysis of the three case studies allowed us to construct a framework that companies can use to effectively implement their digital transformation strategies (Figure 1).

\section{[Insert Figure 1 about here]}

Our cases suggest that the starting point of the effective implementation of a digital transformation strategy is defining the scope of the transformation. ${ }^{103,104}$ In fact, clearly defining what a company wants to achieve is critical to maintaining the focus on the digital transformation aim and to ensure the consistency of each building block with the strategy formulated. Actually, a major output of the strategy formulation process is the definition of 
organization's strategic goals and plans ${ }^{105}$. Consequently, the strategic goals, resulting from the strategy formulation process, are transferred to the strategy implementation process by defining the specific scope to achieve. Thus, favoring the connection between strategy formulation and implementation. A crucial element of a digital transformation strategy, and consequently of our framework, is data. Indeed, data have a central role in the digital economy, ${ }^{106}$ albeit underestimated in the business model literature. In fact, data are considered the enablers of digital transformation, ${ }^{107,} 108$ since their acquisition and analysis trigger specific firm capabilities needed to successfully implement a digital transformation strategy. The most important aspect of data usage is that it must be constantly refreshed. New data need to be continuously collected to support the analyses and data models in a feedback loop. Once collected, cleaned, and securely stored, data are then ready to be elaborated and processed through specific AI techniques ${ }^{109}$ to extract information that feeds the transformed activities, tasks, and services to be executed. Moreover, the extracted information may be processed to expand individuals (i.e., employees) and organizational knowledge base. Concurrently, companies need to define the relevant job roles (and skills), ${ }^{110}$ the strategic partners, and the processes and procedures ${ }^{111}$ needed to support the entire information extraction and knowledge generation process, and thus achieve the scope of the digital transformation. Thereafter, the information and knowledge generated are used to carry out and support the transformed activities, tasks, and services that then create value for customers. $^{112}$

In the following, we discuss each building block of our framework, highlighting its relevance in the implementation of digital transformation strategies. In particular, we use the findings from the three case studies to describe each building block.

Scope. Consistently with the extant literature, we spotted that, to be effective and avoid inefficiencies, companies must have the scope of the digital transformation strategy clearly in 
mind. ${ }^{113,114}$ In particular, this is the cornerstone of defining how the company envisions creating value for its customers and it is defined on the basis of the strategic goals resulting from the strategy formulation process. The scope statement and the sub-goals needed to achieve it directly drive the digital strategy implementation and favor the connection between strategy formulation and strategy implementation. In each of our cases, the scope of the digital transformation was clearly defined as follows:

- ABB: Create continuous value for customers through software and platform enabled services.

- CNHi: Develop new services around predictive maintenance and intelligent logistics through the digitalization of its fleet.

- Vodafone: Automate and improve customer care.

With respect to the scenario before the digital strategy formulation, $\mathrm{CNHi}$ and $\mathrm{ABB}$ aimed at changing their business by creating digital platforms that collect data and leverage them to enable new high added-value services for their customers. Differently, Vodafone aimed at enhancing the value of extant services, as the customer care, by leveraging digital technologies.

Data sources (external and internal). As stated earlier, data are crucial resources for the implementation of a digital transformation strategy. ${ }^{15,116,117}$ Indeed, properly managing data is critical to effectively support the digital transformation of firms, while the peculiar role of data in value creation has been sometimes overlooked and recognized only recently (e.g., 118, 119). The cases suggest that data are commonly sourced from online stores, physical stores, web/apps, IoT devices, social networks, ecosystem, and third parties. In particular, our cases show that companies rely on both internal and external data sources to implement digital transformation strategies. For instance, in the ABB case, the company needed to understand how customers use its products to gain useful insights for the entire organization. 
To achieve this, ABB relied on internal data sources, such as the data provided by IoT devices connected with products, and external data sources, such as consultants, installers, panel builders, and original equipment manufacturers (OEMs). CNHi and Vodafone use internal and external data sources. Notable in both cases is that they use internal sources to capture the most critical data. In fact, CNHi uses sensors on products to determine the status of vehicles, while data sourced from external partners (e.g., retailers, insurance companies, seed and fertilizer supplier) are useful to infer additional insights. Similarly, Vodafone largely relies on internal data obtained from customer interactions, while baseline conversational models allow fine-tuning the service. In line with the literature highlighting the central role of critical resources, as data in our cases, to establish and sustain firm's competitive $\operatorname{advantage}^{120}$, we noticed that the three cases were very careful in ensuring their control over time. Of course, some data sources may be more relevant than others to create value, in which case, companies need to ensure access to these by internalizing them (e.g., using IoT devices to guarantee a continuous data stream from products sold), or by establishing reliable agreements with external sources, such as formal partnerships.

Data platform. Data usually transit via a data platform through which the product itself and all the SaaS (software as a service) and PaaS (platform as a service) are generated and pushed to B2B (business-to-business) and B2C (business-to-consumer) end customers and players in the greater ecosystem ${ }^{121}$. For example, in the ABB case, a digital platform is used to collect data from products and make them available for knowledge extraction needed to provide high value software-enabled services. This means that every action and input starts and ends as a digital signal that assumes different meanings based on the company's business view. In particular, data platforms operate as a place where data are collected from internal and external sources, enriched, and made available through a structured and business-oriented data library. As a result, data can be accessed by different areas of the business to create 
value either through data mining and AI model experimentation or through data services powering business applications and operations. For instance, CNHi's data platform collects data from IoT devices and makes them available for analyses and machine learning model creation by internal data scientists and product managers. Moreover, these platforms often collect end-user data, and must hence be accurately governed and protected in compliance with law (i.e., General Data Protection Regulation in Europe). Due to the confidentiality of the data, CNHi has developed specific encryption, while Vodafone has defined internal policy and privacy guidelines to protect them.

People. Generally, digital transformation entails a thorough revision of the firm's operations and business models, as suggested by extant literature. ${ }^{122}$ However, when substantially revising the activities and processes, new professional roles may be needed. In fact, on one side firms may define new managing role to drive the transformation (e.g. Chief Digital Officer, CDO) ${ }^{123}$, on the other side employees may have to possess specific skills and capabilities to fully seize the opportunities that digital technologies create ${ }^{124,125}$ and render the digital transformation fruitful. To ensure this, $\mathrm{CNHi}$, alongside the Microsoft professionals working on the transformation program, supported its data scientists in developing new technological, programming, and software competences, consistently with its digital transformation strategy. This was essential since the digital transformation project also pushed CNHi to becoming a software developer and, ultimately, adopting an open platform model providing and selling services to third parties. Therefore, professional roles, such as digital advisors, that were involved in supporting and shaping the digital transformation, and a new digital team were created within the CNHi existing IT unit, to support the strategy implementation and execution. In the Vodafone case, the digital transformation project compelled managers of the commercial operations unit to upskill their employees and enhance their capabilities. A call center unit was trained to no longer answer customer calls 
directly, but to design conversational frameworks for the chatbot to be used in serving customer requests. Additionally, these employees were involved in training the conversational models to be more and more accurate and relevant for the customers, through a digital feedback loop process of continuous improvement of the accuracy and relevance of conversations, on the basis of customers' experience. Moreover, a neural network training unit was purposely set up to enable operators to use the new intelligent system, which resulted in new jobs and professions. In particular, the project required employees able to train AI and conversation designers. However, in the ABB case, the approach did not impel employees to dramatically change their routines; in fact, most were able to basically do the same work as before, but with new decision support intelligence.

Partners. The digital transformation of companies may entail a radical change in their core capabilities. In the CNHi case, the company has evolved from offering commercial vehicles to operating connected vehicles, therefore requiring knowledge and competences that significantly differed from the past. As such, defining agreements with partners may support the organization in obtaining new data, capabilities, knowledge, and competences that are crucial for the implementation of the digital transformation strategy. ${ }^{126}$ Partnerships may be established with several types of stakeholders. Principally, the analysis of the cases shows that $\mathrm{ABB}, \mathrm{CNHi}$, and Vodafone needed to establish a partnership with a digital partner, in the specific case Microsoft, to develop the IT infrastructure needed to sustain the digital transformation of their business. In practice, Microsoft performed the role of business and technology partner, accompanying these companies along their digital strategy implementation journey, by providing digital competences that focal companies did not own. Furthermore, other partnerships may be pursued over time to support the implementation of the digital transformation strategy. For instance, CNHi established partnerships with insurance companies and customers to obtain insights on their products and anonymized data 
to enhance AI models governing vehicles digital experience, thus complementing the value creation process by the firm. Finally, ABB defined partnerships with stakeholders as OEMs, distributors, panel builders, in order to improve its offering, by supporting new service design and favoring the development of products' core components. Actually, this is consistent with previous studies highlighting the role of partnerships in favoring the revision and implementation of novel firms' digital strategies ${ }^{127}$. However, in addition to the extant understanding, we systematize the role of partners in a comprehensive framework, showing its connection with other building blocks supporting the implementation of a digital transformation strategy.

AI. In the three cases presented, the data collected are used to develop and test machine learning models deployed for different purposes. Specifically, Microsoft AI technologies were adopted within a rapid insight and data exploration framework to ensure an agile approach to data discovery and value creation. To change the business model and organizational activities, lean analytics and an AI operations framework are needed. In fact, "learn fast and fail fast" is at the core of every approach to data and machine learning model design and experimentation. This approach is a key success factor that allows developing better solutions to existing problems, identifying new patterns in data that promote specific actions, inferring relevant knowledge, and promoting both radical and incremental improvements in products and services. ${ }^{128,}{ }^{129}$ Therefore, a digital business model should define the specific AI strategies and capabilities needed to transform data into information and, eventually, generate knowledge that can be used to create value for customers. Typical examples of AI products are applications using computer vision, facial recognition, autonomous vehicles, virtual agents, machine learning models, natural language processing, artificial neural networks, and big data analytics. In particular, machine learning is used in the three cases presented, and is currently the most relevant and diffused technique to obtain the 
most from data. Moreover, Vodafone uses neural networks to analyze users' natural language queries. Specifically, the relevance of the AI building block is a peculiarity of the digital context, that has not been fully unraveled in previous studies (e.g., ${ }^{130,131}$ ), nonetheless its core importance as emerging from the analysis of the cases.

Information and knowledge. This building block is the output of the data analysis and consistent with the aims of the digital transformation strategy. As in the case of ABB, all the intelligence extracted by the data platform may help the company and different stakeholders understand how customers use the products and the impact of the products themselves on the customers' business (in case of B2B relationships). This process is similar for service companies. In particular, in the CNHi case, data are taken from telematic and telemetry boxes (IoT devices) that are then sent to the cloud where they are computed, cleaned, and modelled to be subsequently forwarded to a control room that proactively uses them to globally monitor all vehicles. Thanks to predictive maintenance models, the control room can send alerts on the status of vehicles and understand how drivers interact with the monitored vehicles. This allows CNHi to provide a new service to their first-party customers and to sell information to third parties in the form of a PaaS. In the Vodafone case, data analysis allows developing enhanced conversation models that result in reshaping the customer care operations, consistently with the digital transformation project objective. Finally, the extracted information may be processed to further increase the individual and the organizational knowledge. The presence of this building block is paramount when implementing a digital transformation strategy, while it has been partially neglected in previous literature on business models ${ }^{132}$.

Processes and procedures. The implementation of a digital transformation strategy may require companies to revise over time the processes and procedures used to create value for customers, since the change that digital technologies entail may be radical. ${ }^{133}$ In fact, the 
literature and the empirical evidence suggests that processes and procedures should be agile and lean when dealing with digital transformation to adapt to the rapid technological change and seize emerging opportunities, thus behaving as start-ups rather than consolidated companies. ${ }^{134}$ Additionally, this building block may also refer to the revision of the formal relationships among employees and to the formation of dedicated business units. For instance, in the ABB case, product managers, operating as in a start-up, drive the business idea through the iterative development of minimum viable products to achieve quick wins. In the CNHi and Vodafone cases, a similar lean approach was found. In fact, at CNHi, the digital transformation project was carried out by adopting experimental and iterative approaches, lowering the barriers between developers and business owners, thus allowing for real-time feedback cycles on the scheduled work. As such, these new processes and procedures supported unravelling the digital transformation strategies through timely checks and refining their implementation for consistency with creating value for customers.

Transformed activities, tasks, and services. Digital companies use the aforementioned information extracted and knowledge generated to perform activities, tasks, and services that create value for customers and allow companies to appropriate that value. Therefore, these should be consistent with the scope underlying the digital transformation strategy and can be split into the core activities, tasks, and services that directly provide value to customers, and complementary, which support the execution of the former ones ${ }^{135}$. In the Vodafone case, the digital transformation had the objective of redefining the way the company listens to and understands end customers. Hence, the information is used to train AI in customer care and provide cognitive services. Along with the transformation of the core activities, the digital transformation also provided Vodafone with the opportunity to use the new and in-depth knowledge of customers to offer personalized products and services. Similarly, ABB exploits information and knowledge to tailor solutions and offer savings to customers, execute 
predictive maintenance, and provide automatic reordering, consistently with its digital transformation scope. The digital transformation project also allowed ABB to offer accurate assistance to customers as a complementary activity. Finally, CNHi uses the information extracted, along with the knowledge generated, to improve activities such as fleet management, failure prediction, remote vehicle monitoring, and enhance the automation capabilities.

Customers. Finally, the last building block of our emerging framework identifies who the digital company creates value for. Actually, the relevance of identifying the customers for whom the firm creates value has been strongly stressed also in previous studies (see, ${ }^{136,137}$ ). In particular, we can distinguish between existing and new customers. The digital transformation project may support the company in creating enhanced value for its existing customer base, and even expand it, allowing the company to increase its revenue streams, as in the CNHi case. Indeed, CNHi strengthened its relationships with the existing customer base as a result of their closer connection in the new business model, aiming to make these relationships more valuable. Moreover, the availability of new data and information also enabled addressing new customer profiles. For instance, ABB added new customers to its existing base, such as OEMs and distributors who benefit from the outcomes of the digital strategy implemented. Of course, customers can be both internal and external with respect to the company. Vodafone's digital transformation project, for example, is targeted at both types of customers, i.e., internal customers, such as other Vodafone business units, and external customers, such as end users.

In sum, the building blocks presented above constitute a framework to support the implementation of a digital transformation strategy. Furthermore, we point out that the building blocks of the framework are representative of the business model elements proposed 
in the extant literature ${ }^{138,139}$. Indeed, the framework presents building blocks related to firm's value proposition and market segments, as the scope and the customers blocks. Then, the central part of the framework, with the data, data platform, AI, information and knowledge, people, and partners building blocks is representative of the value chain structure of the digital business model. Additionally, the transformed activities, tasks, and services are emblematic of the capability of the firm to extract the rent from the value created.

Accordingly this block is connected with the mechanisms used by the firm to appropriate the value provided to the customers. Finally, the relationships among the different elements are defined by the processes and procedures block and by the architecture of the framework.

In the Appendix, we show how the framework is applied to describe the three cases presented in this study.

\section{Conclusions}

The rapid development and pervasive diffusion of digital technologies is increasingly pushing companies to thoroughly revise their business activities. Indeed, an increasing number of companies adopt digital transformation strategies, namely, leveraging digital technologies to radically transform value creation and appropriation. ${ }^{140,141}$ However, a digital transformation strategy also entails challenges. ${ }^{142,143}$ In particular, digital transformation may fail due to the disconnection between the strategy's formulation and its implementation. Therefore, to understand how digital transformation can be effectively implemented, we identify the building blocks underlying the implementation of a digital transformation strategy. Through the analysis of the exemplary ABB, CNHi, and Vodafone cases, three companies that successfully undertook the digital transformation journey assisted by a globally renowned "digital companion", i.e., Microsoft, we constructed a framework that can support companies in digitally transforming their businesses, creating the connection between strategy formulation and strategy implementation. More specifically, this framework serves 
as an actionable guide that can help companies navigate through the challenges associated with the implementation of a digital transformation strategy, and thereby renew their business model, deemed as the conceptual and structural implementation of a strategy. ${ }^{144,145}$

Our study offers some interesting theoretical contributions. First, we contribute to the emerging digital transformation literature ${ }^{146,147,148}$ by discussing how three companies dealt with the implementation of a digital transformation strategy, partnering with an experienced player such as Microsoft. In particular, our explorative study highlights that consistently formulating and implementing a digital transformation strategy by focusing on the building blocks of our framework may foster the ultimate success of the strategy itself. By pointing out the critical building blocks and the relationships that affect the implementation of a digital transformation strategy, our findings support the future development of this novel research stream. Second, our study's findings suggest potentially interesting links between the digital strategy and business model literatures (for example, ${ }^{149}$ ), given the strong interconnection between a strategy and business model. ${ }^{150,151,152}$ In fact, when implementing a digital transformation strategy, a company is required to rethink its business model. In this respect, our findings show that the building blocks highlighted in our framework can sustain this process, reducing the risks and uncertainty. For instance, our framework may support firms implementing a digital transformation strategy in sharply and unambiguously identifying the customers to be addressed; and verify that the transformed activities, tasks, and services actually allow the firm to create and appropriate value with respect to the identified customer base. In other words, the framework may help organizations in achieving appropriateness and internal consistency of the digital transformation strategy implementation process.

Moreover, from a practical point of view, our study supports senior executives in the likelihood of successfully executing a digital transformation journey. In fact, we have 
developed an actionable framework that companies can use to effectively implement a digital transformation strategy and ensure consistency with its formulation.

In addition, the proposed framework is constructed of building blocks that help managers focus on the essential features that constitute a digital transformation strategy. In this regard, our framework can serve as a checklist to ensure that none of the key elements composing the strategy are neglected when senior executives engage in digital strategy implementation.

Like any study, ours has some limitations that offer opportunities for future research. First, our findings are based on three case studies. While the three projects presented were supported by Microsoft, a highly relevant player in the digital transformation ecosystem whose experience helps firms increase the likelihood of a successful digital transformation, further studies could extend the generalizability of our results with additional empirical evidence. Second, while in this study we analyzed three successful digital transformation cases, scrutinizing failed cases may prove particularly useful for comparison and especially a more fine-grained understanding of the challenges and risks inherent in the implementation of a digital transformation strategy. Thus, we encourage scholars to embrace the challenge of collecting data from failed digital transformation attempts that may complement our study's findings and shed further light on the dark side of digital strategy implementation. Furthermore, our inductively developed framework, despite offering a detailed and nuanced description of the way firms can effectively implement a digital strategy, does not take into account the possible effect of changes in the external environment, for example, the introduction of a disruptive technology, an increase of the number of partners endowed with complementary assets, or modifications in the structure of a sector. Such contextual and sectorial aspects ${ }^{153}$ may generate feedback loops, and we encourage dynamic applications of this framework aimed at understanding how firms respond to changes in the external environment. Additionally, data may trigger specific firm capabilities favoring the successful 
implementation of a digital transformation strategy. Future research may specifically focus on the analysis of these capabilities (e.g., ${ }^{154,155}$ ), thus providing a complete picture on how the collection and extraction of information from data allow firms to generate and strengthen those capabilities needed to provide value for customers. In conclusion, further studies may also investigate the implementation of a digital transformation strategy with higher granularity, by analyzing in more depth the role and the features of each of the building blocks in our framework. For instance, a relevant field of investigation would be the analysis of the risks connected with the wrong definition of the building blocks, to identify the relevance of the risks and how companies may mitigate them to increase their performance. For instance, further research may focus on unraveling issues as what happens if companies fail to understand the proper AI technologies to be used to create value, which building blocks are more critical for the success of the strategy implementation and if they are different for different industries, and, finally, which feedback loops or other mechanisms may be put in place in order to avoid inappropriate implementation of the digital transformation strategy.

\title{
Appendix
}

In this appendix, we report the framework applied to the three cases analyzed: ABB (Figure A1), CNHi (Figure A2), and Vodafone (Figure A3).

\author{
[Insert Figure A1 about here] \\ [Insert Figure A2 about here] \\ [Insert Figure A3 about here]
}


1 Gianvito Lanzolla, Jamie Anderson, “Digital Transformation,” Business Strategy Review, 19/2 (2008): 72-76.

2 Hajar Fatorachian, Hadi Kazemi, "A critical investigation of Industry 4.0 in manufacturing: Theoretical operationalization framework," Production Planning \& Control, 29/8 (2018): 633644.

3 Lorenzo Ardito, Antonio Messeni Petruzzelli, Umberto Panniello, Achille Claudio Garavelli, "Towards Industry 4.0: Mapping digital technologies for supply chain management-marketing integration," Business Process Management Journal, 25/2 (2019): 323-346.

4 Marco Iansiti, Karim R. Lakhani, "Digital Ubiquity: How Connections, Sensors, and Data are Revolutionizing Business," Harvard Business Review, 92/11 (2014): 90-99.

5 Federico Pigni, Gabriele Piccoli, Richard Watson, "Digital Data Streams: Creating Value from the Real-Time Flow of Big Data," California Management Review, 58/3 (2016): 5-25.

6 Karl S.R. Warner, Maximilian Wäger, "Building dynamic capabilities for digital transformation: An ongoing process of strategic renewal," Long Range Planning, 52/3 (2019): 326-349.

7 Satish Nambisan, "Digital Entrepreneurship: Toward a Digital Technology Perspective of Entrepreneurship," Entrepreneurship: Theory and Practice, 41/6 (2017): 1029-1055.

8 Gianvito Lanzolla, Jamie Anderson, "The Digital Revolution is over. Long Live the Digital Revolution!” Business Strategy Review, 21/1 (2010): 74-77.

9 Federico Pigni et al., op. cit.

10 Volker Tresp, J. Marc Overhage, Markus Bundschus, Shahrooz Rabizadeh, Peter A. Fasching, Shipeng Yu, "Going Digital: A Survey on Digitalization and Large-Scale Data Analytics in Healthcare," Proceedings of the IEEE, 104/11 (2016): 2180-2206.

11 Andrea Urbinati, Davide Chiaroni, Vittorio Chiesa, Federico Frattini, "The Role of Digital Technologies in Open Innovation Processes: An Exploratory Multiple Case Study Analysis," $R \& D$ Management, 50/1 (2020): 136-160.

12 Satish Nambisan, op. cit.

13 Satish Nambisan, op. cit.

14 Federico Pigni et al., op. cit.

15 Carmelo Cennamo, Juan Santaló, "How to Avoid Platform Traps," Sloan Management Review, 57/1 (2015): 12-17.

16 Thomas H. Davenport, George Westerman, "Why so Many High-Profile Digital Transformations Fail," Harvard Business Review, 9 March 2018, https://hbr.org/2018/03/whyso-many-high-profile-digital-transformations-fail.

17 Gerald C. Kane, Doug Palmer, Anh Ngueyn Phillips, David Kiron, Natasha Buckley, "Strategy, Not Technology, Drives Digital Transformation," MIT Sloan Management Review and Deloitte University Press, 14 (2015): 1-25.

18 Barry Libert, Megan Beck, Yoram Wind, "7 Questions to Ask before Your Next Digital Transformation," Harvard Business Review, 14 July 2016, https://hbr.org/2016/07/7-questions-to-ask-before-your-next-digital-transformation\#.

19 Michael Beer, Russel A. Eisenstat, "The silent killer of strategy implementation and learning," MIT Sloan Management Review, 41/4 (2000): 29-40.

20 Victoria L. Crittenden, William F. Crittenden, "Building a capable organization: The eight levers of strategy implementation," Business Horizons, 51/4 (2008): 301-309. 
21 Simon Chanias, Michael D. Myers, Thomas Hess, "Digital Transformation Strategy Making in Pre-Digital Organizations: The Case of a Financial Services Provider," Journal of Strategic Information Systems, 28/1 (2019): 17-33.

22 Charles H. Noble, "The Eclectic Roots of Strategy Implementation Research," Journal of Business Research, 45/2 (1999): 119-134.

23 Xavier Gimbert, Josep Bisbe, Xavier Mendoza, "The Role of Performance Measurement Systems In Strategy Formulation Processes,” Long Range Planning, $43 / 4$ (2010): 477-197.

24 Frank T. Rothaermel, Strategic Management, 3rd edition, McGraw Hill, New York: US (2017).

25 Frank T. Rothaermel, op. cit.

26 Rainer Feurer, Kazem Chaharbaghi, John Wargin, "Analysis of strategy formulation and implementation at Hewlett-Packard," Management Decision, 33/10 (1995): 4-16.

27 Rony Dayan, Peter Heisig, Florinda Matos, "Knowledge management as a factor for the formulation and implementation of organization strategy," Journal of Knowledge Management, 21/2 (2017): 308-329.

28 Michael Beer, Russel A. Eisenstat, op. cit.

29 Victoria L. Crittenden, William F. Crittenden, op. cit.

30 Eucman Lee, Phanish Puranam, "The implementation imperative: Why one should implement even imperfect strategies perfectly," Strategic Management Review, 37/8 (2016): 1529-1546.

31 Charles R. Greer, Robert F. Lusch, Michael A. Hitt, "A service perspective for human capital resources: A critical base for strategy implementation," Academy of Management Perspectives, 31/2 (2017): 137-158.

32 Simon Chanias et al, op. cit.

33 Eucman Lee, Phanish Puranam, op. cit.

34 Charles R. Greer et al, op. cit.

35 Geoff Colvin, "What the Hell Happened at GE?" Fortune, 177/6 (2018), http://fortune.com/longform/ge-decline-what-the-hell-happened/.

36 Geoff Colvin, op. cit.

37 Michael Beer, Russel A. Eisenstat, op. cit.

38 Victoria L. Crittenden, William F. Crittenden, op. cit.

39 Eucman Lee, Phanish Puranam, op. cit.

40 Charles R. Greer et al, op. cit.

41 James Richardson, "The Business Model: An Integrative Framework for Strategy Execution," Strategic Change, 17/5-6 (2008): 133-144.

42 Ramon Casadesus-Masanell, Joan Enric Ricart, "From Strategy to Business Models and Onto Tactics," Long Range Planning, 43/2-3 (2010): 195-215.

43 Gianvito Lanzolla, Jamie Anderson, "Digital Transformation."

44 Satish Nambisan, op. cit.

45 Gianvito Lanzolla, Jamie Anderson, "The Digital Revolution is over. Long Live the Digital Revolution!"

46 Charles H. Noble, op. cit.

47 Xavier Gimbert, op. cit.

48 Gianvito Lanzolla, Jamie Anderson, "Digital Transformation."

49 Satish Nambisan op. cit.

50 Gianvito Lanzolla, Jamie Anderson, “The Digital Revolution is over. Long Live the Digital Revolution!" 
51 Karl S.R. Warner, Maximilian Wäger, op. cit.

52 Simon Chanias et al, op. cit.

53 Day-Yang Liu, Shou-Wei Chen, Tzu-Chuan Chou, "Resource fit in digital transformation: Lessons learned from the CBC Bank global e-project," Management Decision, 49/10 (2011): 1728-1742.

54 Saul J. Berman, "Digital transformation: Opportunities to create new business models," Strategy \& Leadership, 40/2 (2012): 16-24.

55 Feng Li, "The digital transformation of business models in the creative industry: A holistic framework and emerging trends," Technovation, (2018), in press.

56 Kurt Matzler, Stephan Friedrich von den Eichen, Markus Anschober, Thomas Kohler, "The Crusade of Digital Disruption,” Journal of Business Strategy, 39/6 (2018): 13-20.

57 Marco Iansiti, Karim Lakhani, op. cit.

58 Frank T. Rothaermel, op. cit.

59 David J. Teece, "Business Models and Dynamic Capabilities," Long Range Planning, 51/1 (2018): 40-49.

60 Erik Brynjolfsson, Andrew McAfee, "Winning the Race with Ever-Smarter Machines," MIT Sloan Management Review, 53/2 (2012): 53-60.

61 Thomas H. Davenport, George Westerman, op cit.

62 Marc de Swaan Arons, Frank van den Driest, Keith Weed, "The Ultimate Marketing Machine," Harvard Business Review, 92/7-8 (2014): 54-63.

63 Marc de Swaan Arons et al., op. cit.

64 George Westermann, Didier Bonnet, Andrew McAfee, Leading Digital: Turning Technology into Business Transformation, Harvard Business Review Press, Boston: US (2014).

65 Thomas H. Davenport, George Westerman, op. cit.

66 Mike Wilson, "Nike's Big Bet on the Future of Connected Shoes," Fast Company, 15 January 2019, https://www.fastcompany.com/90291303/nikes-big-bet-on-the-future-of-connected-shoes

67 Gerald C. Kane et al, op. cit.

68 Thomas Hess, Christian Matt, Alexander Benlian, Florian Weisböck, "Options for Formulating a Digital Transformation Strategy," MIS Quarterly Executive, 15/2 (2016): 123-139.

69 Morteza Ghobakhloo, "The future of manufacturing industry: A strategic roadmap toward Industry 4.0," Journal of Manufacturing Technology Management, 29/6 (2018): 910-936.

70 Ramon Casadesus-Masanell, Joan Enric Ricart, op. cit.

71 Karl S.R. Warner, Maximilian Wäger, op. cit.

72 Alessio Cozzolino, Gianmario Verona, Frank T. Rothaermel, "Unpacking the Disruption Process: New Technology, Business Models, and Incumbent Adaptation," Journal of Management Studies, 55/7 (2018): 1166-1202.

73 Ramon Casadesus-Masanell, Joan Enric Ricart, op. cit.

74 Alexander Osterwalder, Yves Pigneur, Christopher L. Tucci, "Clarifying business models: Origins, present, and future of the concept," Communications of the Association for Information Systems, 16/1 (2005): 1-25.

75 Ramon Casadesus-Masanell, Joan Enric Ricart, op. cit.

76 James Richardson, op. cit.

77 Marcelo Nogueira Cortimiglia, Antonio Ghezzi, Alejandro Germán Frank, "Business Model Innovation and Strategy Making Nexus: Evidence from a Cross-Industry Mixed-Methods Study," R\&D Management, 46/3 (2016): 414-432.

78 Alexander Osterwalder et al, op. cit. 
79 Nicolai J. Foss, Tina Saebi, "Fifteen years of research on business model innovation: How far have we come, and where should we go?" Journal of Management, 43/1 (2017): 200-227.

80 Tina Saebi, Lasse Lien, Nicolai J. Foss, "What drives business model adaptation? The impact of opportunities, threats and strategic orientation," Long Range Planning, 50/5 (2017): 567-581.

81 James Richardson, op. cit.

82 David J. Teece, op. cit.

83 Marco Iansiti, Karim R. Lakhani, op. cit.

84 Tina Saebi et al, op. cit.

85 Satish Nambisan, op. cit.

86 Saul J. Berman, "Digital Transformation: Opportunities to Create New Business Models," Strategy \& Leadership, 40/2 (2012): 16-24.

87 Marco Iansiti, Karim R. Lakhani op. cit.

88 Christoph Zott, Raphael Amit, Lorenzo Massa, "The Business Model: Recent Developments and Future Research," Journal of Management, $37 / 4$ (2011): 1019-1042.

89 Federico Pigni et al., op. cit.

90 Alexander Osterwalder, Yves Pigneur, Business Model Generation, John Wiley \& Sons, Hoboken, New Jersey (2010).

91 Kathleen M. Eisenhardt, "Building Theories from Case Study Research," Academy of Management Review, 14/4 (1989): 532-550.

92 Robert K. Yin, Case Study Research: Design and Methods, 3rd edition, Sage Publications: Thousand Oaks, California (1984).

93 Andrew H. van de Ven, Engaged Scholarship - A Guide for Organizational and Social Research, Oxford University Press, Oxford, United Kingdom (2007).

94 Satya Nadella, Greg Shaw, Jill Tracie Nichols, Hit Refresh: The Quest to Rediscover Microsoft's Soul and Imagine a Better Future for Everyone, HarperCollins Publishers, New York, USA (2017), p. 126.

95 Robert K. Yin, op. cit.

96 Andrew H. van de Ven, op. cit.

97 Nicolai J. Foss, Tina Saebi, op. cit.

98 Tina Saebi et al., op. cit.

99 Kathleen M. Eisenhardt, op. cit.

100 Nicolai J. Foss, Tina Saebi, op. cit.

101 Tina Saebi et al., op. cit.

102 Kathleen M. Eisenhardt, op. cit.

103 Kurt Matzler et al., op. cit.

104 Wendy K. Smith, Andy Binns, Michael L. Tushman, "Complex Business Models. Managing Strategic Paradoxes Simultaneously," Long Range Planning, 43/2-3 (2010): 448-461

105 Frank T. Rothaermel, op. cit.

106 Federico Pigni et al., op. cit.

107 Claudia Loebbecke, Arnold Picot, "Reflections on Societal and Business Model Transformation arising from Digitization and Big Data Analytics: A Research Agenda," The Journal of Strategic Information Systems, 24/3 (2015): 149-157.

108 Wendy Arianne Günther, Mohammad H. Rezazade Mehrizi, Marleen Huysman, Frans Feldberg, "Debating Big Data: A Literature Review on Realizing Value from Big Data," The Journal of Strategic Information Systems, 26/3 (2017): 191-209. 
109 Jacques Bughin, Brian McCarthy, Michael Chui, "A Survey of 3,000 Executives Reveals how Business Succeed with AI," Harvard Business Review, August 28 (2017),

https://hbr.org/2017/08/a-survey-of-3000-executives-reveals-how-businesses-succeed-with-ai.

110 Federico Pigni et al., op. cit.

111 Thomas Hess et al., op. cit.

112 Alexander Osterwalder, Yves Pigneur, op. cit.

113 Kurt Matzler et al., op. cit.

114 Wendy K. Smith et al., op. cit.

115 Federico Pigni et al., op. cit.

116 Claudia Loebbecke, Arnold Picot, op. cit.

117 Wendy Arianne Günther et al., op. cit.

118 Marco Iansiti, Karim R. Lakhani, op. cit.

119 Alina Sorescu, "Data-driven business model innovation," Journal of Product Innovation Management, 34/5 (2017): 691-696.

120 Jay Barney, "Firm resources and sustained competitive advantage," Journal of Management, 17/1 (1991): 99-120.

121 Robert Bock, Marco Iansiti, Karim R. Lakhani, "What the companies on the right side of the digital business divide have in common," Harvard Business Review, 31 January 2017, https://hbr.org/2017/01/what-the-companies-on-the-right-side-of-the-digital-business-dividehave-in-common.

122 Gianvito Lanzolla, Jamie Anderson, "Digital Transformation."

123 Anna Singh, Patricia Klamer, Thomas Hess, "How do chief digital officers pursue digital transformation activities? The role of organization design parameters," Long Range Planning, (2019), in press.

124 Federico Pigni et al., op. cit.

125 Thomas D. Davenport, "Competing on Analytics," Harvard Business Review, 84/1 (2006): 98107.

126 Marco Iansiti, Karim R. Lakhani, op. cit.

127 Angela Andal-Ancion, Phillip A. Cartwright, Georges S. Yip, "The digital transformation of traditional businesses," MIT Sloan Management Review, 44/4 (2003): 34-41.

128 Jacques Bughin et al., op. cit.

129 Rob van der Meulen, "5 Ways Data Science and Machine Learning Impact Business," Gartner, February 6 (2018), https://www.gartner.com/smarterwithgartner/5-ways-data-science-andmachine-learning-impact-business/.

130 Gerald C. Kane et al, op. cit.

131 Karl S.R. Warner, Maximilian Wäger, op. cit.

132 Alexander Osterwalder, Yves Pigneur, op. cit.

133 Wendy Arianne Günther et al., op. cit.

134 Kurt Matzler et al., op. cit.

135 David J. Teece, op. cit.

136 Christoph Zott et al., op. cit.

137 María Luz Martín-Peña, Eloísa Díaz-Garrido, José María Sánchez-López, “The digitalization and servitization of manufacturing: A review on digital business models," Strategic Change, 27/2 (2018): 91-99.

138 Nicolai J. Foss, Tina Saebi, op. cit. 
139 Tina Saebi et al., op. cit.

140 Marco Iansiti, Karim R. Lakhani, op. cit.

141 Federico Pigni et al., op. cit.

142 Carmelo Cennamo, Juan Santaló, op. cit.

143 Thomas H. Davenport, George Westerman, op. cit.

144 James Richardson, op. cit.

145 Ramon Casadesus-Masanell, Joan Enric Ricart, op. cit.

146 Gianvito Lanzolla, Jamie Anderson, "Digital Transformation."

147 Satish Nambisan, op. cit.

148 Gianvito Lanzolla, Jamie Anderson, "The Digital Revolution is over. Long Live the Digital Revolution!"

149 David J. Teece, op. cit.

150 James Richardson, op. cit.

151 Ramon Casadesus-Masanell, Joan Enric Ricart, op. cit.

152 Marcelo Nogueira Cortimiglia et al., op. cit.

153 Alfredo De Massis, Josip Kotlar, Mike Wright, Franz. W. Kellermanns, "Sector-Based Entrepreneurial Capabilities and the Promise of Sector Studies in Entrepreneurship," Entrepreneurship Theory and Practice, 42/1 (2018): 3-23.

154 Omar A. El Sawy, Pernille Kræmmergaard, Henrik Amsinck, Anders Lerbech Vinther, "How LEGO built the foundations and enterprise capabilities for digital leadership," MIS Quarterly Executive, 15/2 (2016): 141-166.

155 David J. Teece, op. cit. 
Table 1. Overview of the Three Case Studies

\begin{tabular}{|c|c|c|c|}
\hline & ABB & CNHi & Vodafone \\
\hline Business & Electrical equipment & Agricultural equipment & TLC \\
\hline Size & $\begin{array}{c}\text { 147,000 employees } \\
\text { (2018) }\end{array}$ & $\begin{array}{c}\text { 63,000 employees } \\
\text { (2017) }\end{array}$ & $\begin{array}{c}111,000 \text { employees } \\
(2018)\end{array}$ \\
\hline Headquarters & $\begin{array}{c}\text { Zurich } \\
\text { (Switzerland) }\end{array}$ & $\begin{array}{c}\text { Amsterdam } \\
\text { (The Netherlands) }\end{array}$ & $\begin{array}{c}\text { London } \\
\text { (United Kingdom) }\end{array}$ \\
\hline Founded & 1988 & 2012 & 1991 \\
\hline $\begin{array}{l}\text { Main objective } \\
\text { of the digital } \\
\text { transformation } \\
\text { project }\end{array}$ & $\begin{array}{l}\text { Develop smart products } \\
\text { that allow providing } \\
\text { value added services to } \\
\text { customers }\end{array}$ & $\begin{array}{c}\text { Develop autonomous } \\
\text { unmanned agricultural } \\
\text { machines endowed with } \\
\text { AI }\end{array}$ & $\begin{array}{c}\text { Improve customer care } \\
\text { services using } \\
\text { conversational } \\
\text { autonomous interfaces } \\
\text { based on AI operating } \\
\text { through a number of } \\
\text { channels (web, apps, } \\
\text { social networks, etc.) }\end{array}$ \\
\hline $\begin{array}{l}\text { Start of digital } \\
\text { transformation } \\
\text { project }\end{array}$ & 2016 & 2018 & 2017 \\
\hline $\begin{array}{l}\text { Number of } \\
\text { employees } \\
\text { involved }\end{array}$ & $\begin{array}{l}30 \text { employees working } \\
\text { in R\&D, Product } \\
\text { Management, Sales, } \\
\text { Marketing, and } \\
\text { Communication }\end{array}$ & $\begin{array}{l}30 \text { employees including } \\
\text { Commercial Vehicles } \\
\text { and Industry specific } \\
\text { Vehicles Unit Managers } \\
\text { working in IT and } \\
\text { Operations, and } \\
\text { Executive Business } \\
\text { Stakeholders }\end{array}$ & $\begin{array}{l}23 \text { employees working } \\
\text { in Commercial } \\
\text { Operations Unit and } 5 \\
\text { employees working in } \\
\text { IT }\end{array}$ \\
\hline
\end{tabular}


Figure 1. The Digital Strategy Implementation Framework

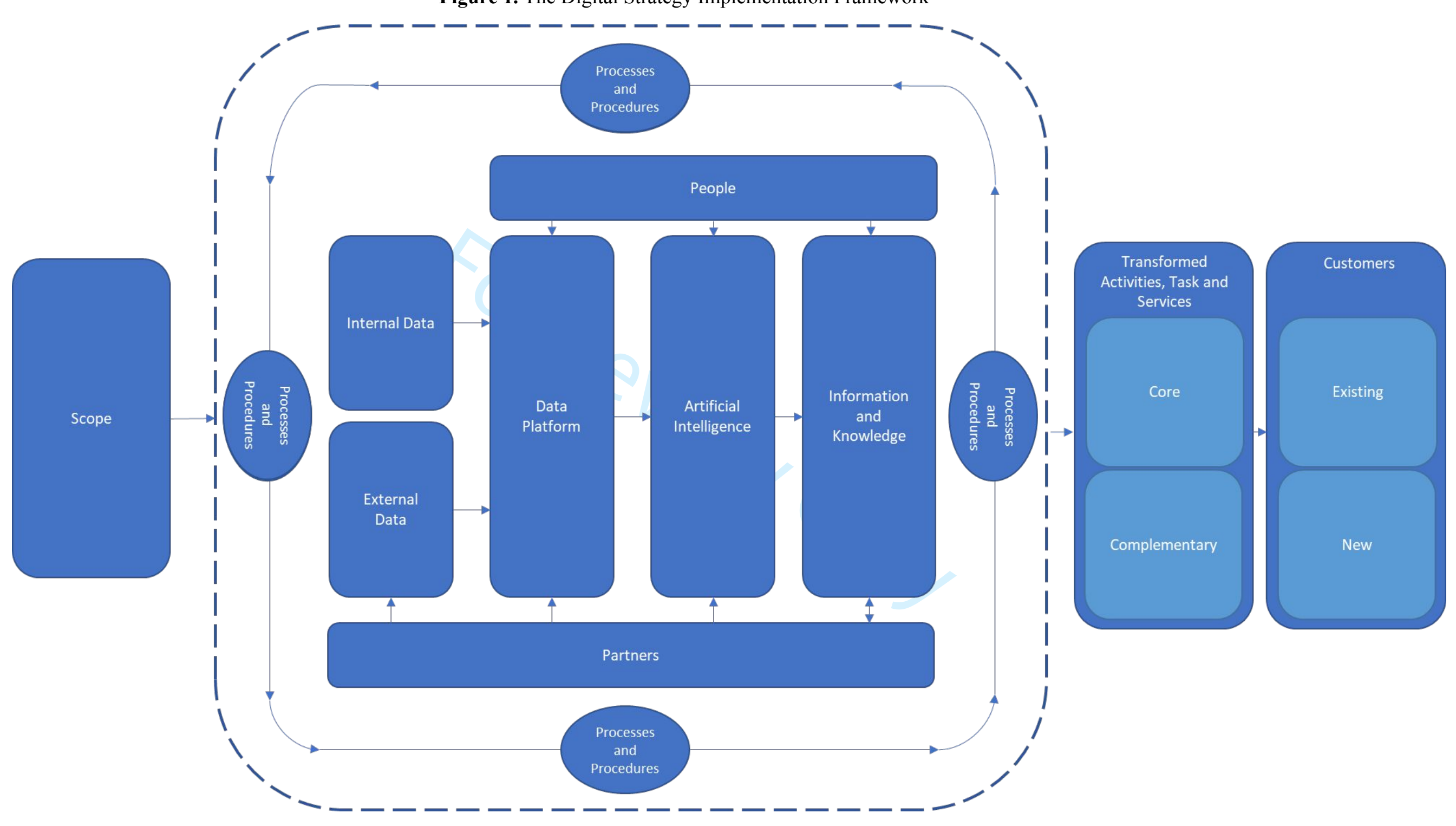


Figure A1. The Framework applied to the ABB case

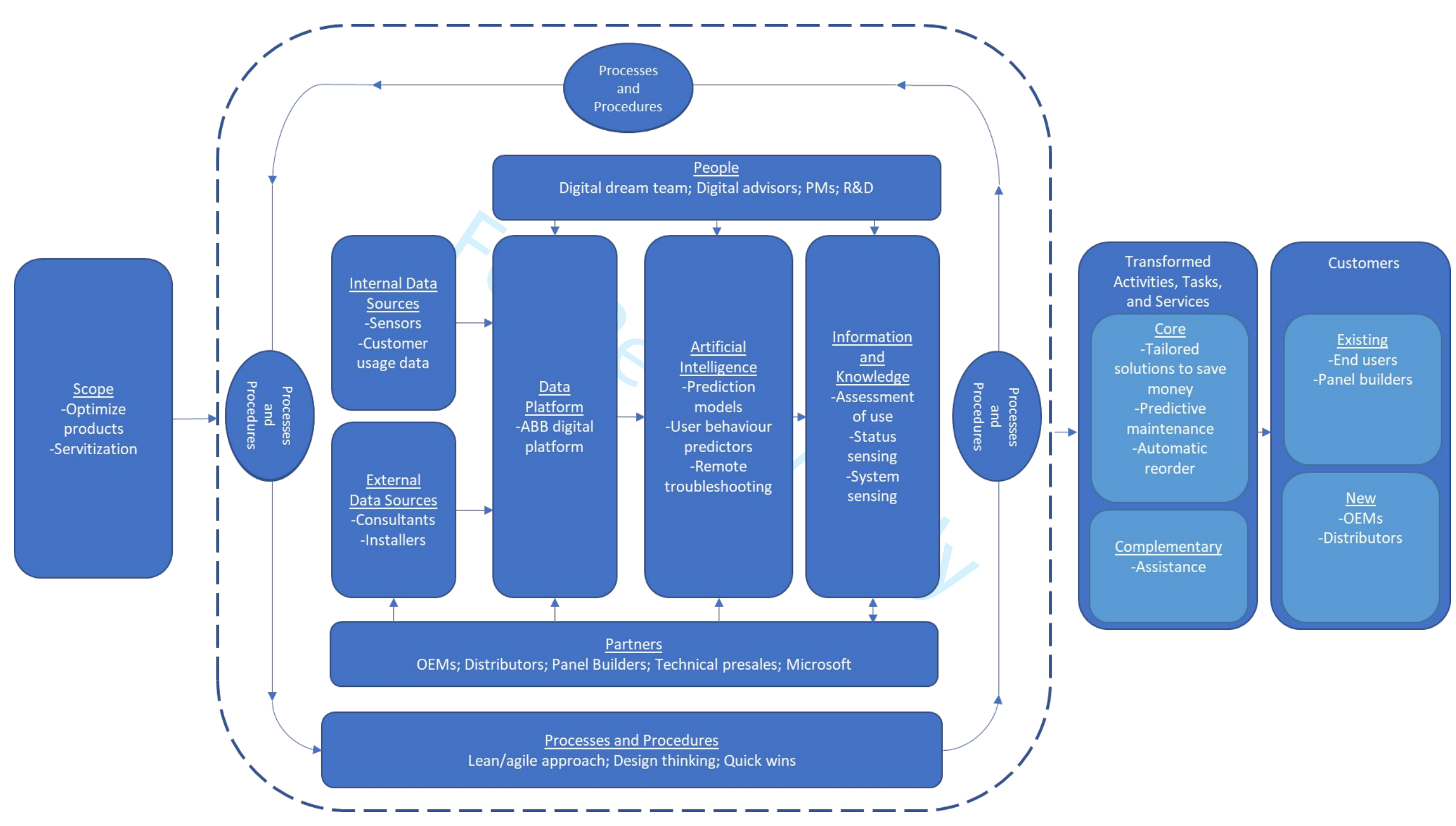


Figure A2. The Framework applied to the CNHi Case

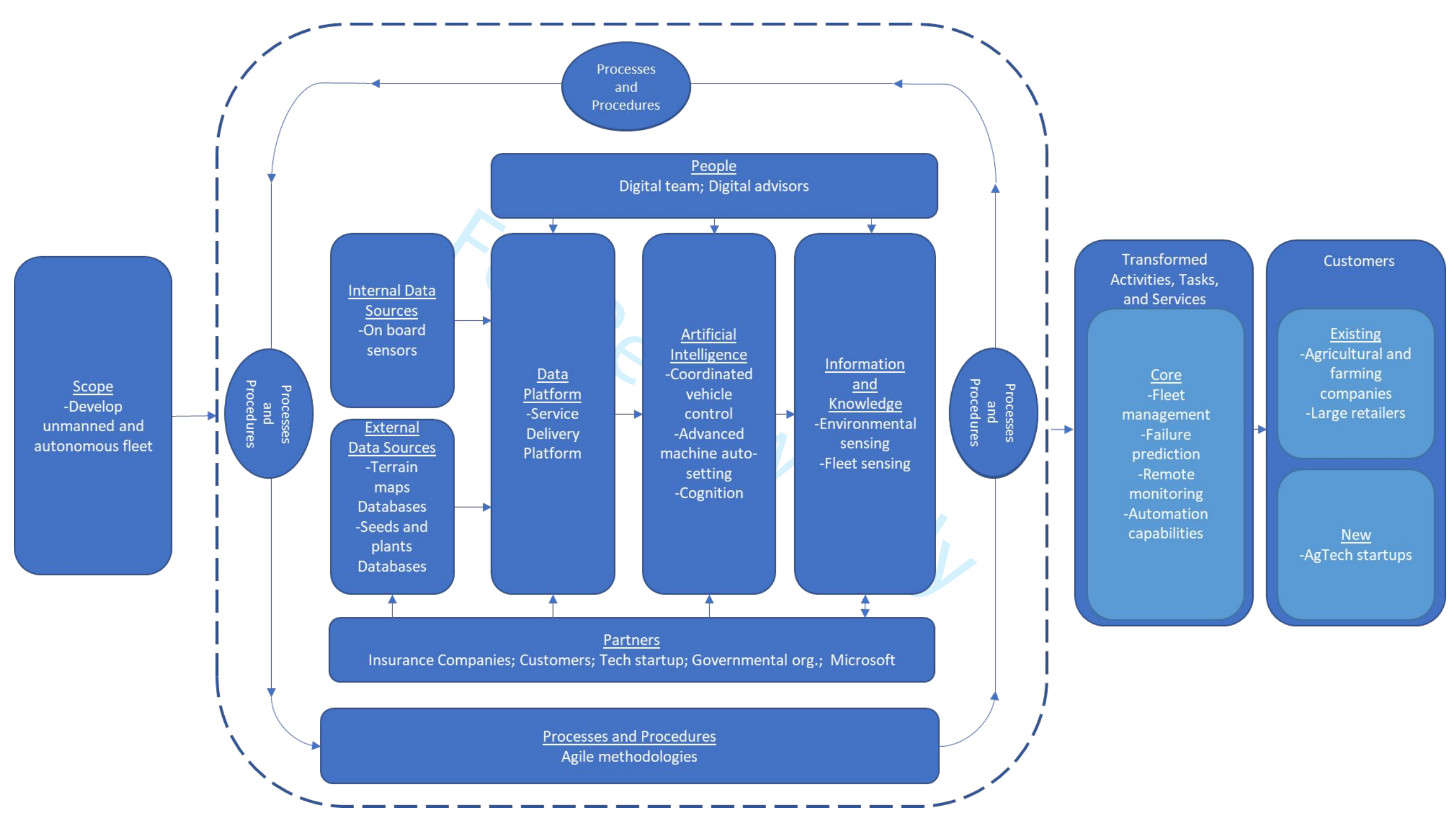


Figure A3. The Framework applied to the Vodafone case

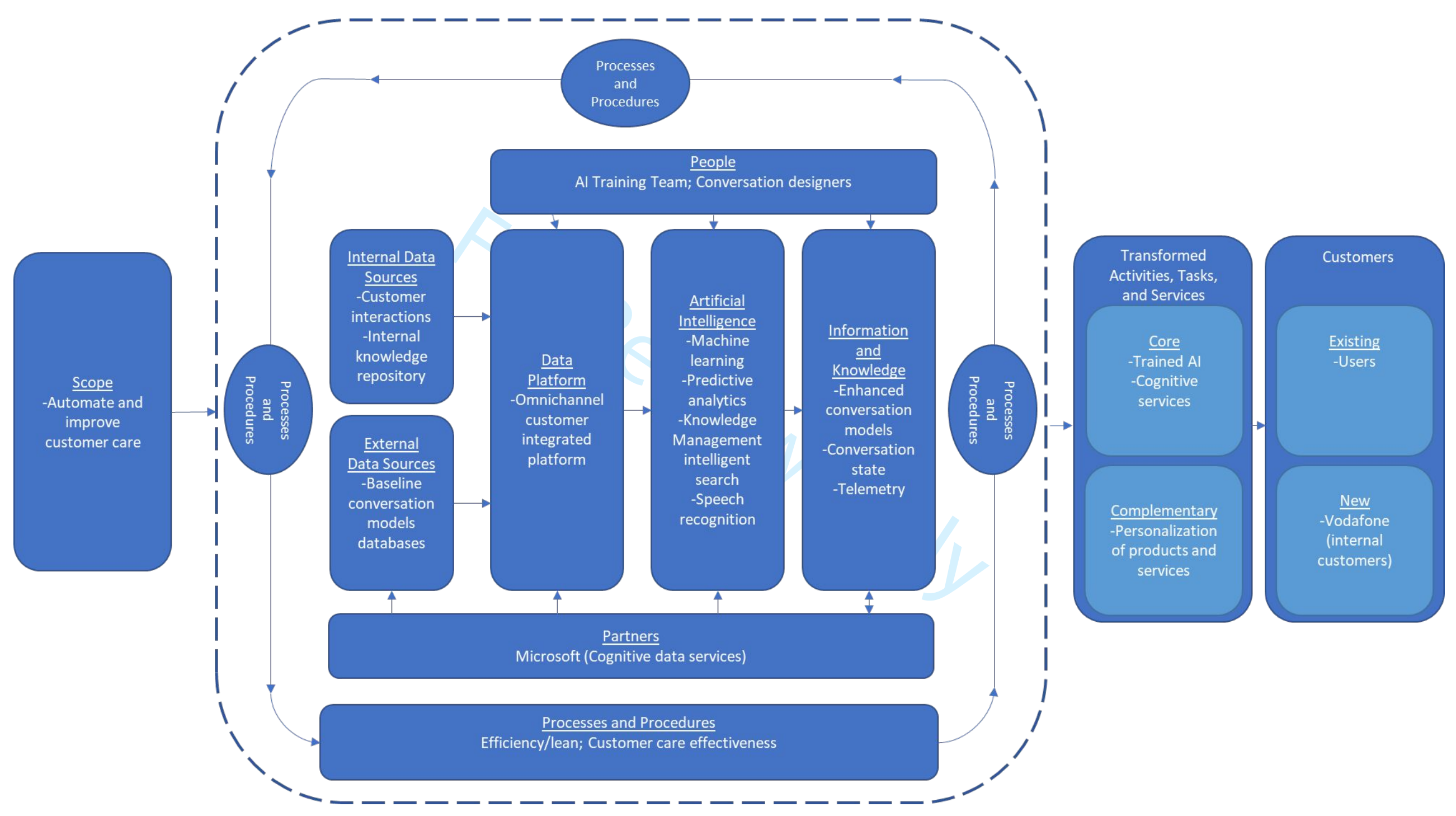




\section{CMR-03-19-000002-IP-DT.R1}

POINT TO POINT RESPONSE TO THE REVIEWERS

We would like to thank the Reviewers for their careful review of our manuscript and for providing us constructive comments and indications on how to improve the quality of the manuscript.

For the sake of clarity, in the following paragraphs, we report each Reviewers' comment and our response in italics afterwards.

\section{$\underline{\text { Reviewer } 1}$}

Overall, I am stratified with the revisions.

A minor improvement would be showing relationships between findings/proposed model and existing examples of digital transformation present in the extant literature. See for instance (Ardito et al., 2019; Bienhaus \& Haddud, 2018; Fatorachian \& Kazemi, 2018; Ghobakhloo, 2018; Moeuf et al., 2018)

Ardito, L., A. Messeni Petruzzelli, U. Panniello, and A. C. Garavelli. (2019). Towards Industry 4.0: Mapping digital technologies for supply chain management-marketing integration. Business Process Management Journal 25(2): 323-346.

Bienhaus, F., and A. Haddud. (2018). Procurement 4.0: factors influencing the digitisation of procurement and supply chains. Business Process Management Journal 24(4): 965-984.

Fatorachian, H., and H. Kazemi. (2018). A critical investigation of Industry 4.0 in manufacturing: theoretical operationalisation framework. Production Planning \& Control 29(8): 633-644.

Ghobakhloo, M. (2018). The future of manufacturing industry: a strategic roadmap toward Industry 4.0. Journal of Manufacturing Technology Management 29(6): 910-936.

Moeuf, A., R. Pellerin, S. Lamouri, S. Tamayo-Giraldo, and R. Barbaray. (2018). The industrial management of SMEs in the era of Industry 4.0. International Journal of Production Research 56(3): 1118-1136.

We are thankful to the Reviewer for her/his helpful comments that helped us in increasing the value of our work and we are happy that the previous version of our manuscript satisfied the Reviewer. According to the minor comment provided, we read the suggested papers and mentioned the most relevant of them in our discussion, in order to further tighten our study to the extant literature.

\section{$\underline{\text { Reviewer } 2}$}

Dear Authors,

Thank you very much for the revised version of your manuscript. 
The manuscript has been improved in the Conceptual Background and Introduction. Nonetheless, I think that you still need to work on the findings section and data analysis that have not been properly revised.

We are grateful to the Reviewer for her/his constructive comments and for appreciating the revisions performed.

Albeit your link to business model literature is clearer than in the previous version in the conceptual background, I would recommend your data analysis better moves from business model dimensions (as I also recommended in my previous review). In particular, at page 7 you say: "from a strategic viewpoint, business models are made of four main components: (i) the firm's value proposition and market segments, (ii) the structure of the value chain, (iii) the mechanisms used by the firm to appropriate value provided, and (iv) the relationships among these elements". You have not mentioned them in your data analysis and final framework... Consequently, there is a mismatch between the conceptual background and the findings that may make readers confused. If business model is relevant, you need to show it also in the results and framework.

We agree with the suggestion provided. According to the comment, we revised the Research Design and Methodology section to specify how the typical business model elements proposed in the literature (Foss and Saebi, 2017; Saebi et al., 2017) were actually helpful in the identification of the building blocks included in our framework. Furthermore, we revised the Findings section to explicitly clarify how each building block of the proposed framework is related to the business model elements mentioned.

Additionally, in your reply, you say that you compared the emerging results with the literature, "to spot confirming and conflicting findings", but I do not find evidence in the text: which are the dimensions that diverge/are similar? (And why is it the case?). You mentioned Birkinshaw et al. (2016)'s paper on CMR: please consider following their reasoning (providing first an organizing framework in the Conceptual Background section) and then detailing your three cases better.

We thank the reviewer for pointing out this issue. Actually, we revised the Findings section highlighting more clearly differences and similarities with the extant literature with regard to the proposed building blocks. Indeed, we believe that this suggestion helped us in further clarifying our contributions to the extant literature. Finally, we considered the possibility to apply the approach used by Birkinshaw et al. (2016). However, we noticed that, while the framework discussed by Birkinshaw et al. (2016) is deeply rooted in the extant literature, our framework, due to the explorative nature of our study, emerges from the analysis of the case studies. Due to this reasoning, we opted for the adoption of a different approach with respect to the paper by Birkinshaw et al. (2016).

Thanks for the reply about polar cases. However, you completely disregarded my comment about taking a longitudinal perspective that, I think, would have improved your model a lot.

Thank you for this comment. Also in this case, we considered the possibility to adopt a longitudinal perspective. However, since the main result of our study is the definition of the framework and we did 
not focus in depth on the whole digital transformation journey, we deemed the perspective used to present the cases as the most consistent with the our findings.

In the discussion section you say "In this respect, our findings show that the building blocks highlighted in our framework can sustain this process, reducing the risks and uncertainty.". Please, provide some examples. Please also add some academic references to the capabilities topic in the Discussion (they were extremely interesting in the previous version!). Also, provide an example about what do you mean with "For instance, a relevant field of investigation would be the analysis of the risks connected with the wrong definition of the building blocks, to identify the relevance of the risks and how companies may mitigate them to increase their performance." since it is very broad.

We are thankful to the Reviewer for these comments on the Conclusion section. We actually agree that some points in the discussion needed further clarification. Therefore, according to the Reviewer's suggestions, we revised the discussion, providing further examples and references where needed.

Good luck with this paper.

We would like to thank again the Reviewer for her/his comments and for the positive feedback about our study. We think the comments and the suggestions provided helped us in enhancing the overall value and impact of our study.

\section{$\underline{\text { Reviewer } 3}$}

I'm OK with the progress.

We are thankful to the Reviewer for her/his comments and for the positive attitude towards our study.

I have only two comments that should be addressed:

- Why does the pervasiveness of new digital technologies reduce barriers across industries? I think you should explain for sentence.

Thank you very much for pointing out this issue. Accordingly, we clarified the mentioned sentence in the Introduction, providing also related examples. In particular, we highlighted that digital transformation favours the interconnection among different industries, by leading firms in reaping new opportunities to create and appropriate value through the digitization and connectivity (Nambisan, 2017).

- The sentence "the existing body of knowledge implicitly assumes that once a digital transformation strategy has been defined, implementation will follow" should be justified with at least an additional reference.

We would like to thank the Reviewer for suggesting this revision, which helped us in providing more theoretical support to the sentence. In particular, we cited the studies by Feuer et al. (1995) and Dayan et al. (2017).

We would like to thank again the Reviewer for supporting us in improving the overall value and impact of our manuscript. 


\section{References}

Julian Birkinshaw, Alexander Zimmermann, Sebastian Raisch, "How do firms adapt to discontinuous change? Bridging the dynamic capabilities and ambidexterity perspectives," California Management Review, 58/4 (2016): 36-58.

Nicolai J. Foss, Tina Saebi, "Fifteen years of research on business model innovation: How far have we come, and where should we go?," Journal of Management, 43/1 (2017): 200-227.

Rainer Feurer, Kazem Chaharbaghi, John Wargin, "Analysis of strategy formulation and implementation at Hewlett-Packard," Management Decision, 33/10 (1995): 4-16.

Rony Dayan, Peter Heisig, Florinda Matos, "Knowledge management as a factor for the formulation and implementation of organization strategy," Journal of Knowledge Management, 21/2 (2017): 308329.

Satish Nambisan, "Digital Entrepreneurship: Toward a Digital Technology Perspective of Entrepreneurship," Entrepreneurship: Theory and Practice, 41/6 (2017): 1029-1055.

Tina Saebi, Lasse Lien, Nicolai J. Foss, "What drives business model adaptation? The impact of opportunities, threats and strategic orientation," Long Range Planning, 50/5 (2017): 567-581. 